
Mr Nikola Pekić,
poručnik, pilot
VP 3020
Batajnica

\section{REZULTATI MODELIRANJA BORBENOG MANEVRA NAPADA AVIONA NA ZEMALJSKI CILJ IZ OŠTROG OBRUŚAVANJA}

UDC: $519.711: 629.7 .072: 623.746 .3$

Rezime:

U ovom radu prikazani su rezultati matematičkog modeliranja kretanja aviona $u$ borbenom manevru pri napadu na zemaljski cilj iz oštrog obrušavanja. Kretanje aviona razmatrano je kao kretanje materijalne tačke u prostoru. Takode, prikazane su prednosti aviona sa otklonom vektora potiska i njegove primene u manevru u odnosu na avion sa klasičnom pogonskom grupom i klasičnim aerodinamičkim upravljačkim površinama.

Ključne reči: oštro obrušavanje, otklon vektora potiska, normalno opterećenje, smanjenje visine leta.

\title{
THE RESULTS OF COMBAT ATTACK MANEUVER MODELLING ON GROUND TARGET USING SIRCRAFT STEEP DIVING
}

Summary:

This paper presents the results of mathematical modeling of aircraft movement in combat maneuver during attack on ground target using steep diving. Aircraft movement is considered as movement of a material point in space. Also, the advantages of aircraft with thrust vector deflection and its applications during maneuver when compared to the aircraft with classical engines and classical aerodynamic controls.

Key words: combat aircraft, combat maneuver, steep diving, thrust vector deflection, normal load, steady aircraft lowering.

\section{Uvod}

Visoka pokretljivost (manevribilnost) i veliki specifični potisak savremenih aviona lovačkobombarderske avijacije, u kombinaciji sa izborom odgovarajućeg naoružanja, obezbeđuju njihovo efektivno korišćenje za bombarderska dejstva po različitim ciljevima na zemlji. Obrušavanje, kao etapa borbenog leta aviona, koristi se pri napadu na zemaljski cilj. Ono predstavlja kretanje aviona, približno po pravolinijskoj putanji $u$ intervalu $\Delta \mathrm{t}_{\mathrm{p}}$, koji je potreban za dovođenje avio-naoružanja na cilj. Oštro obrušava- nje karakteriše se velikim uglovima nagiba trajektorije, koji su, po modulu, veći od 40 do $45^{\circ}$.

\section{Oštro obrušavanje aviona}

Savremeni avioni sa motorima bez zakretnih sistema (bez otklona vektora potiska) izvršavaju obrušavanje obično pri frekvenciji obrtanja rotora motora koja odgovara režimu malog gasa $\Omega_{\mathrm{mg}}$. Pri tom je potisak motora zanemarljiv, i iznosi $P_{M G} \cong 0$. Minimalan potisak motora je neophodan radi smanjenja tangencijalnog ubrzanja aviona u obrušavanju. Rast brzi- 
ne leta dovodi do „neprijatnog“ (za pilota) uvećanja minimalno dozvoljene daljine otvaranja vatre, po uslovima preleta zone rasturanja parčadi, kao i do udaljavanja od cilja tačke početka uvođenja aviona $\mathrm{u}$ obrušavanje [1]. Prema tome, moguće je prekoračenje maksimalno dozvoljene brzine leta. Radi povećanja sile otpora aviona, pri obrušavanju se preporučuje korišćenje vazdušnih kočnica, ako njihovo izvlačenje ne dovodi do promena po napadnim uglovima i uglovima klizanja, tj. do usložavanja dovođenja aviona na cilj.

$\mathrm{Na}$ slici 1 prikazana je šema sila, koje deluju na avion u obrušavanju, sa motorima bez zakretnih sistema. Napadni ugao je pozitivan $\alpha>0$ a koeficijent normalnog opterećenja $n_{z}$ je $u$ funkciji ugla nagiba putanje $i$ iznosi $n_{z}=\cos \theta$.

Koeficijent tangencijalnog opterećenja zavisi od sile otpora aviona pri uspostavljanju obrušavanja $\mathrm{n}_{\mathrm{x}}=\sin \theta$.

Šema sila, koje deluju pri obrušavanju na avion sa otklonom vektora potiska motora nagore u odnosu na uzdužnu osu aviona prikazana je na slici 2 .

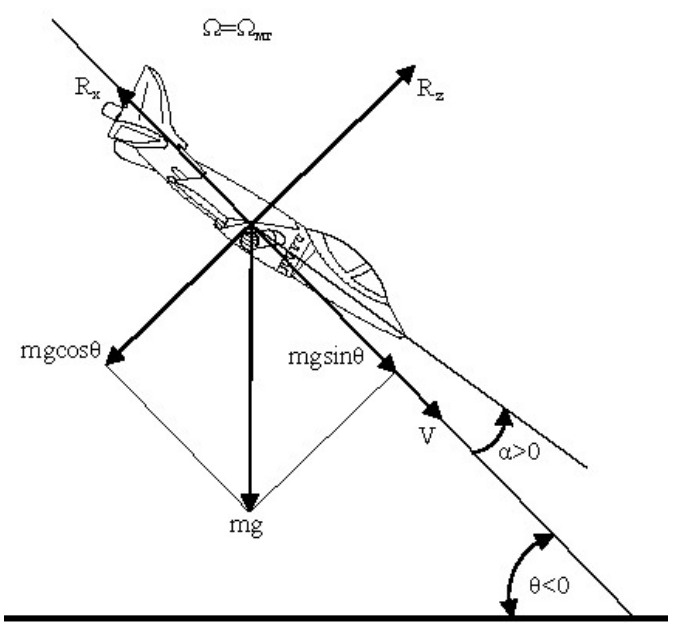

Sl. 1 - Šema sila koje deluju na avion u obrušavanju sa motorima bez vektorisanja potiska, napadni ugao je pozitivan $(\alpha>0)$

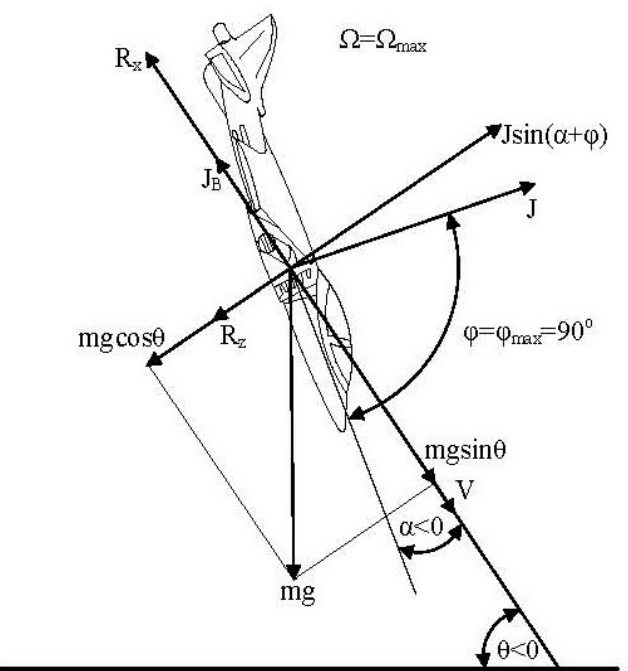

Sl. 2 - ̌̌ema sila koje deluju na avion, pri obrušavanju, sa otklonom vektora potiska motora nagore u odnosu na uzdužnu osu aviona

Vektor sile na izlazu iz motora J otklonjen je na maksimalan ugao $\phi=\phi_{\max }=90^{\circ}$ radi upravljanja normalnim i tangencijalnim ubrzanjem aviona. Sila na ulasku u usisnik $\mathrm{J}_{\mathrm{v}} \mathrm{i}$ čeoni otpor $\mathrm{R}_{\mathrm{x}}$ usmereni su na kočenje aviona. Sila $J_{v}$ pri maksimalnom režimu rada motora $\Omega_{\max }$ doprinosi održanju zadate brzine leta $u$ toku oštrog obrušavanja aviona. Ravnoteža normalnih sila (slika 2) u toku obrušavanja izražava se na sledeći način:

$-J \sin (\alpha+\varphi)+R_{z}+m g \cos \theta=0$

gde je:

J - sila potiska;

$\alpha$ - napadni ugao;

$\varphi$ - ugao otklona vektora potiska;

$\mathrm{R}_{\mathrm{z}}$ - sila uzgona;

$\mathrm{mg}$ - masa aviona;

$\theta$ - ugao nagiba putanje.

Dakle, kod aviona sa velikim specifičnim potiskom $\mu=\frac{J}{m g}$, ova ravnoteža 
se obezbeđuje silom uzgona $R_{z}$ sa negativnim napadnim uglom $\alpha$.

Polarni dijagram ustaljenog smanjenja visine leta, $\mathrm{u}$ manevru, aviona bez otklona $(\phi=0)$ i sa otklonom vektora potiska motora $(\phi \neq 0)$ prikazan je na slici 3 .

Osnovne aerodinamičke i taktičko-tehničke karakteristike razmatranog aviona odgovaraju dozvučnom jurišniku A10: startni specifični potisak $\mu_{0}=0,55 \mathrm{i}$ specifično opterećenje krila $p_{0}=3600$ $\mathrm{N} / \mathrm{m}^{2}$. Kod jurišnika bez otklona vektora potiska $(\phi=0)$ sa izvučenim vazdušnim kočnicama maksimalni ugao ustaljenog snižavanja ne prelazi $35^{\circ}$. Sa otklonom vektora potiska motora na ugao $\phi_{\max }=$ $90^{\circ}$ i bez izvlačenja vazdušnih kočnica, ugao snižavanja (obrušavanja) jurišnika dostiže vrednost od $58^{\circ}$.

Matematički model kretanja aviona sa otklonom vektora potiska motora sačinjen je u programskom jeziku Fortran [1]. Rezultati modeliranja borbenog manevra napada na zemaljski cilj iz obrušavanja, avionom sa otklonom vektora potiska motora, prikazani su na slikama $4 \mathrm{i}$ 5. Početni uslovi manevra odgovaraju

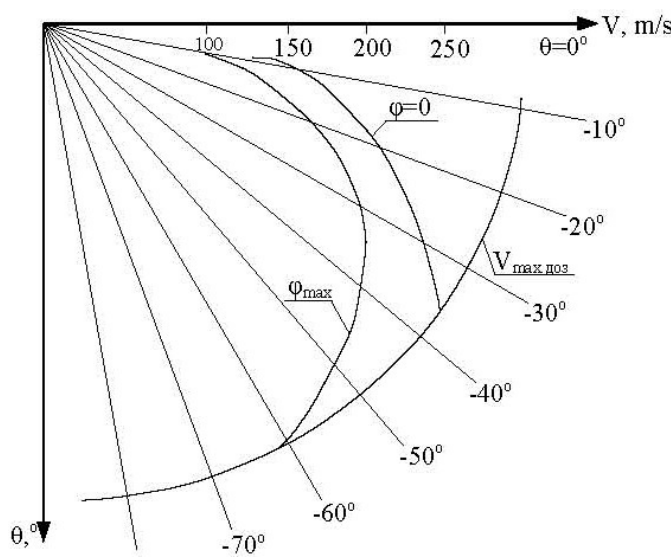

Sl. 3 - Polarni dijagram ustaljenog smanjenja visine leta aviona bez otklona $(\phi=0) i s a$ otklonom vektora potiska motora $(\phi \neq 0)$ bočnoj udaljenosti aviona $\mathrm{x}_{3}=3 \mathrm{~km} \mathrm{u}$ momentu preleta traverze zemaljskog cilja $\mathrm{x}_{1}=0$ na visini $\mathrm{x}_{2}=50 \mathrm{~m}$ (slika 4 ).

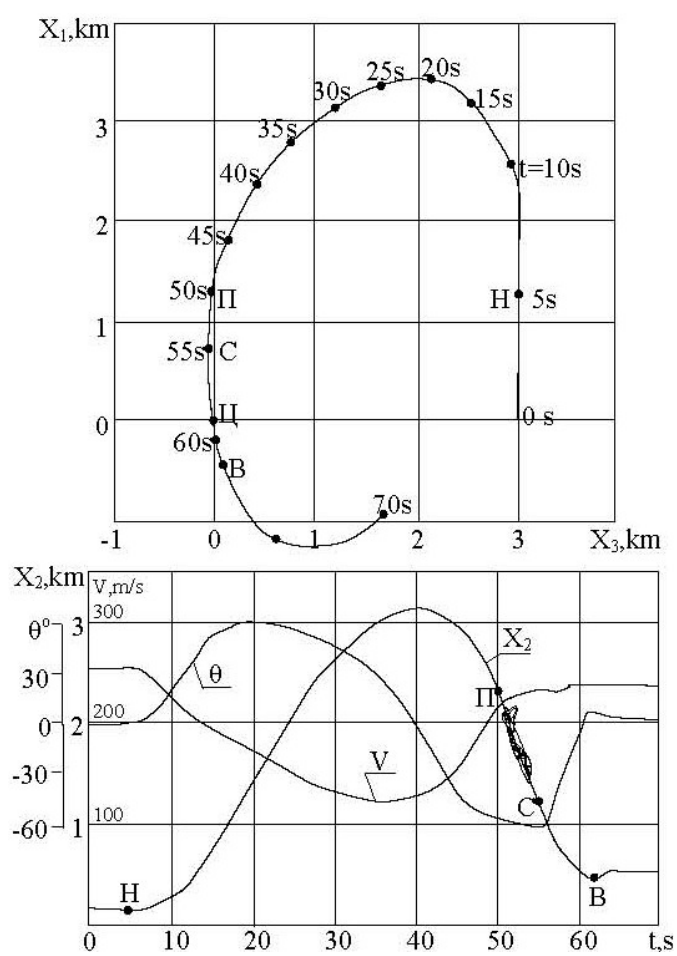

Sl. 4 - Projekcija manevra u horizontalnoj $i$ vertikalnoj ravni i promena parametara leta aviona sa vektorisanim potiskom u manevru

$\mathrm{Na}$ delu horizontalnog leta $(\mathrm{ON})$ ugao nagiba putanje aviona je $\gamma=0$, koeficijent normalnog opterećenja je $n_{\mathrm{z}}=1$, relativni potisak motora $\overline{\mathrm{P}}=0,27 \mathrm{i}$ ugao otklona vektora potiska iznosi $\phi=0$ (slika 5). Trenutak $\mathrm{t}=5 \mathrm{~s}$ odgovara početku (t.N) etape zalaza aviona na zemaljski cilj (NP na slici 4). U 45. sekundi avion se uvodi u tačku početka obrušavanja $(\mathrm{P})$ sa uglom $-60^{\circ}$ pri brzini leta $\mathrm{V}=200 \mathrm{~m} / \mathrm{s}$. Greška u pravcu vektora brzine na cilj u tački $\mathrm{P}$ ne prelazi $2^{\circ}$.

Karakter promene funkcija upravljanja u funkciji vremena prikazan je na slici 5. Vektor potiska motora otklanja se na ugao $\phi=90^{\circ}$ pri uvođenju u obruša- 


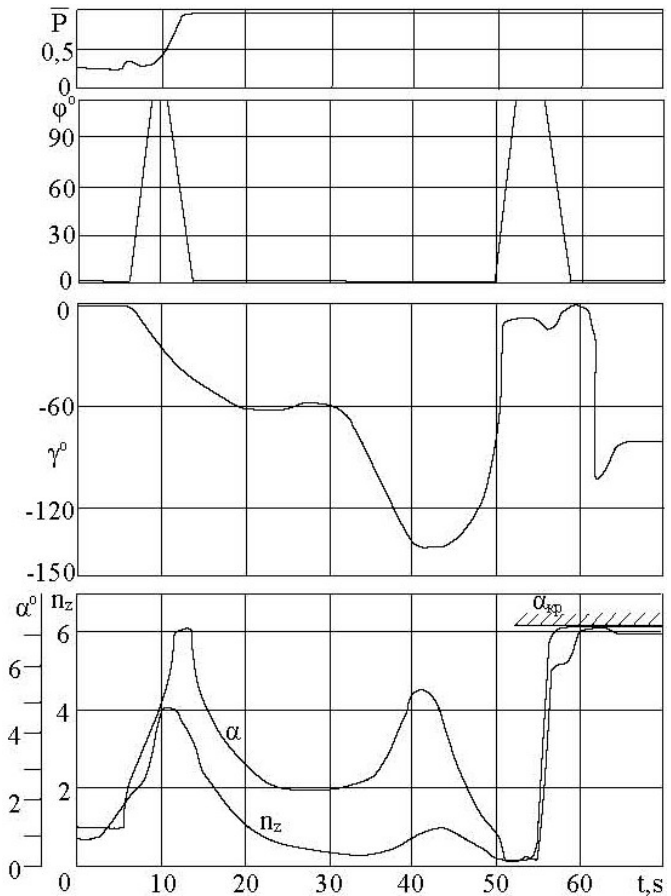

Sl. 5 - Promena parametara leta aviona sa promenom vektora potiska u manevru u funkciji vremena

vanje za povećanje normalnog opterećenja i u obrušavanju za kočenje (usporenje) aviona. Brzina aviona na kraju obrušavanja ne prelazi vrednost $230 \mathrm{~m} / \mathrm{s}$. Na etapi obrušavanja (PS) upravljanje avionom obezbeđuje se promenom napadnog ugla $\alpha$ i uglom bočnog nagiba $\gamma$ u dijapazonu: $0 \leq n_{z} \leq 2,0 ; \quad|\gamma| \leq 30^{\circ}$. Pri pomenutim uslovima obezbeđuje se tačno dovođenje vektora brzine aviona na zemaljski cilj sa greškom u trenutku otvaranja vatre (t.S) ne većom od 5 mrad. „Vađenje" iz obrušavanja vrši se opterećenjem, od 6 g jedinica, pri čemu napadni ugao $\alpha$ dostiže dozvoljenu kritičnu vrednost $\alpha_{\mathrm{kr}}$. Nakon vađenja iz obrušavanja avion obavlja zaokret na stalnoj visini sa uglom bočnog nagiba $\gamma=-80^{\circ}$.

Povećanje ugla obrušavanja $(\theta)$ dovodi do smanjenja koeficijenta normal- nog opterećenja aviona $n_{z}=\cos \theta$. Pri vertikalnom obrušavanju ugao nagiba putanje je $\theta=-90^{\circ}$, a koeficijent normalnog opterećenja iznosi $n_{z}=0$. U tom slučaju upravljanje bočnim odstupanjem aviona od zemaljskog cilja putem promene ugla bočnog nagiba je neefikasno.

Pri oštrom obrušavanju ograničeni dijapazon promene koeficijenta normalnog opterećenja $0 \leq n_{z} \leq 2,0$ i ugla bočnog nagiba $|\gamma| \leq 30^{\circ}$ ne obezbeđuje tačno dovođenje aviona na zemaljski cilj. Zbog toga je potrebno izvršiti pariranje

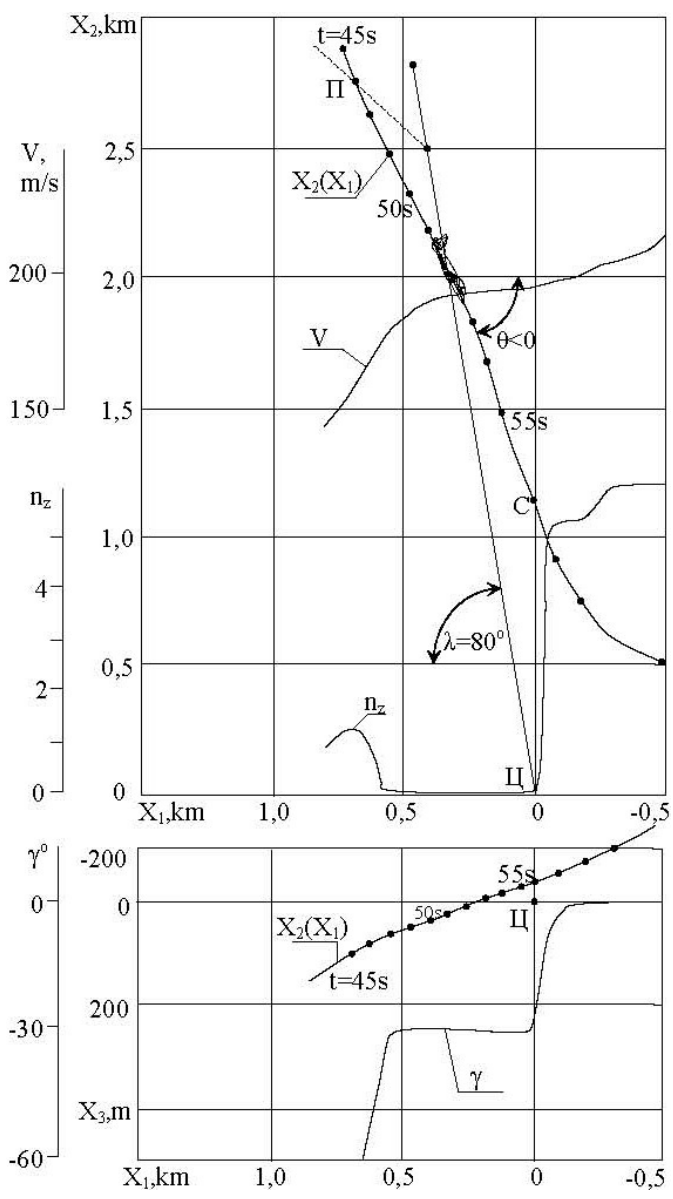

Sl. 6-Promena parametara leta aviona sa vektorisanim potiskom u obrušavanju u funkciji vremena za zadati ugao obrušavanja od $-80^{\circ}$ 
spoljašnjim poremećajima, koji deluju na avion u toku obrušavanja i otkloniti greške vođenja aviona u tački početka obrušavanja po uglu pravca vektora brzine aviona na zemaljski cilj. Na slici 6 prikazani su rezultati modeliranja oštrog obrušavanja jurišnika sa otklonom vektora potiska motora. Zadati ugao obrušavanja je $\theta=-80^{\circ}$.

Međutim, u tačku $P$ početka obrušavanja avion se dovodi sa nepovoljnom

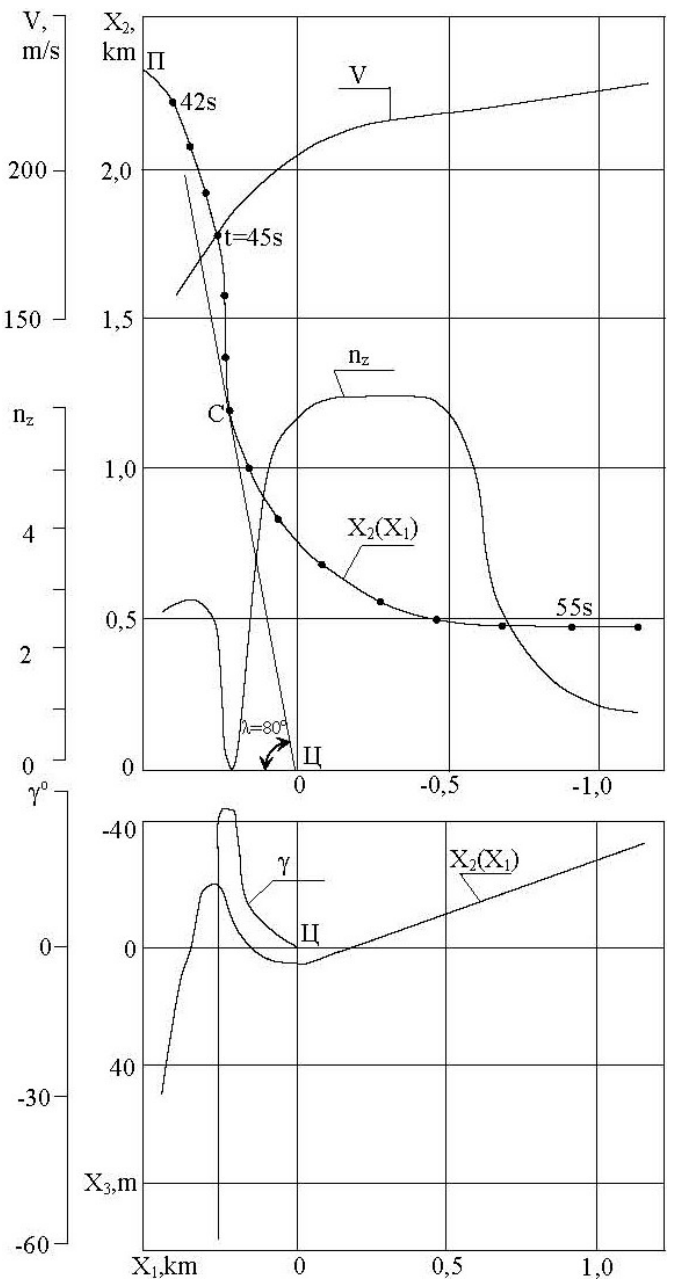

Sl. 7 - Promena parametara leta aviona sa vektorisanim potiskom u završnom delu obrušavanja u funkciji vremena za zadati ugao obrušavanja od $-80^{\circ}$ greškom po uglu nagiba putanje napada na zemaljski cilj, tj. vektor brzine odstupa više od linije nišanjenja na zemaljski cilj $\left(|\lambda|-\left|\theta_{0}\right|=10^{\circ}\right.$; slika 6$)$. Greška po putnom uglu ne prelazi $\Delta \psi=5^{\circ}$. Na etapi dužeg obrušavanja (dužeg za 10 sekundi) korišćenje graničnih funkcija upravljanja $\left(n_{z}=0\right.$ i $\left.\gamma=-30^{\circ}\right)$ ne obezbeđuje usklađivanje pravca vektora brzine sa linijom nišanjenja na zemaljski cilj.

Proširenje dijapazona promene koeficijenta normalnog opterećenja i ugla nagiba putanje $u$ obrušavanju ograničeno je uslovima radne sposobnosti pilota $\mathrm{i}$ karakteristikama rada nišanskog sistema. Negativno normalno opterećenje ne koristi se u skladu sa oštrom promenom karaktera upravljanja bočnom udaljenošću aviona od zemaljskog cilja putem stvaranja bočnog nagiba [3]. Zaista, pri pozitivnom normalnom opterećenju $\mathrm{n}_{\mathrm{z}}>0$ za zaokret aviona udesno neophodan je pozitivan ugao bočnog nagiba $\gamma>0$. Međutim, pri promeni predznaka opterećenja $\mathrm{n}_{\mathrm{z}}<0$ za zaokret aviona udesno potreban je ugao bočnog nagiba suprotnog predznaka $\gamma<0$. Promena karaktera upravljanja avionom, u zavisnosti od predznaka koeficijenta normalnog opterećenja, moguća je u toku nišanjenja ali realizacija takvog upravljanja moguća je samo sistemom automatskog upravljanja. Promena ugla bočnog nagiba $u$ intervalu $\gamma= \pm 150^{\circ}$ pri zadržavanju uslova $n_{z}>0$ obezbeđuje, kako pokazuju rezultati modeliranja, navođenje aviona na zemaljski cilj sa oštrim obrušavanjem pod uglom $\theta=-80^{\circ}$ (slika 7). Međutim, to navođenje ostvaruje se sa toliko oštrom i značajnom promenom ugla bočnog nagiba i koeficijenta normalnog opterećenja da u praksi ručno upravljanje avionom smanjuje verovatnoću uspešne realizacije datog manevra. 
Razmotriće se mogućnost upravljanja avionom u obrušavanju pri ograničenom dijapazonu promene koeficijenta normalnog opterećenja $\left(0 \leq n_{z} \leq 2\right)$ i ugla bočnog nagiba $\left(|\gamma| \leq 30^{\circ}\right)$. Ocena graničnih promena putnog ugla i ugla nagiba putanje $\left(\Delta \psi_{\mathrm{t}}\right.$ i $\left.\Delta \theta\right)$ obaviće se $\mathrm{u}$ zavisnosti od početnog ugla obrušavanja $\theta_{o}$ pri graničnim vrednostima koeficijenta opterećenja, nagiba i dužine trajanja obrušavanja koje iznosi 5 sekundi. Proračun uglova $\Delta \psi_{\mathrm{t}}$ i $\Delta \theta$ izvodi se sa pretpostavkom da konstantna srednja brzina $\mathrm{u}$ obrušavanju iznosi $\mathrm{V}=100-250 \mathrm{~m} / \mathrm{s}$.

Pozitivan prirast ugla nagiba trajektorije $\Delta \theta>0$, u zavisnosti od njegove početne

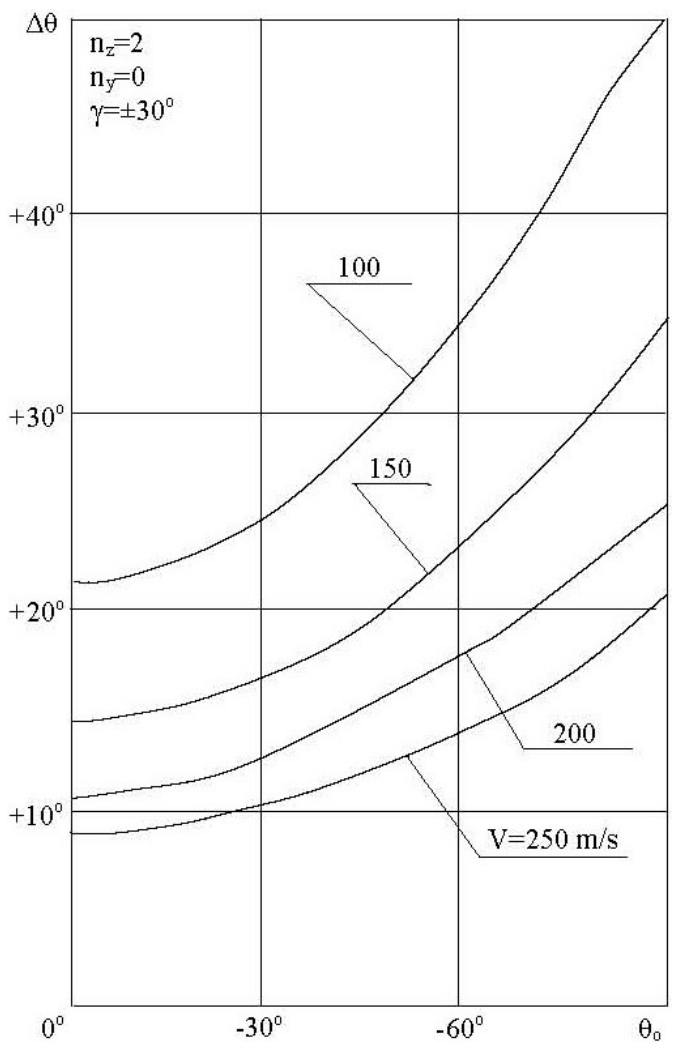

Sl. 8 - Zavisnost prirasta ugla nagiba trajektorije $\Delta \theta>0$ od njegove početne vrednosti $\theta_{o}$ pri $n_{z}=2$; $\gamma= \pm 30^{\circ} i$ nultog bočnog opterećenja $\left(n_{y}=0\right)$ vrednosti $\theta_{o}$ pri $n_{z}=2 ; \gamma= \pm 30^{\circ}$ i nultog koeficijenta bočnog opterećenja $\left(\mathrm{n}_{\mathrm{y}}=0\right)$, prikazan je na slici 8. Povećanjem ugla obrušavanja vrednost koeficijenta normalnog opterećenja se smanjuje, jer je $n_{z o}=\cos \theta_{0}$, što dovodi do rasta rezerve koeficijenta normalnog opterećenja za upravljanje letom za vrednost $\Delta n_{z}=2-\cos \theta_{0} i$ do povećanja pozitivnog prirasta ugla nagiba putanje $\Delta \theta>0$ u odnosu na početni $\theta_{\mathrm{o}}$.

Povećanjem brzine leta $\mathrm{V}$ veličina $\Delta \theta$ se smanjuje. Negativan prirast ugla nagiba putanje $\Delta \theta<0$ u odnosu na početni ugao $\theta_{\circ}$ obezbeđuje se smanjenjem koeficijenta normalnog opterećenja do nule. Zavisnost $\Delta \theta\left(\theta_{\mathrm{o}}\right)$ za taj slučaj prikazana

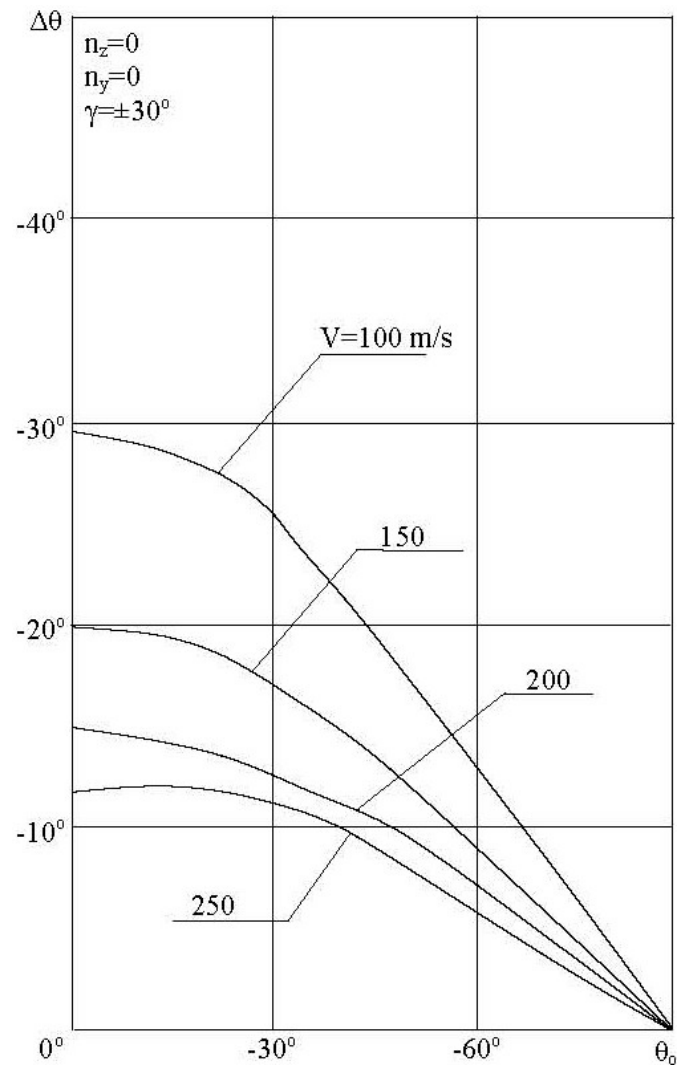

Sl. 9 - Zavisnost negativnog prirasta ugla nagiba trajektorije $\Delta \theta<0$ u odnosu na početni $\theta_{o}$ 
je na slici 9. Povećanjem ugla obrušavanja mogućnost upravljanja avionom posredstvom normalnog opterećenja se smanjuje, $\Delta \mathrm{n}_{\mathrm{z}}=0-\cos \theta_{0}$, i promena ugla $\Delta \theta$ se smanjuje do nulte vrednosti pri $\theta_{\mathrm{o}}=-90^{\circ}$.

Dovođenje vektora brzine na zemaljski cilj obezbeđuje se jednovremeno po uglu nagiba putanje i po putnom uglu. Promena putnog ugla pri $\gamma= \pm 30^{\circ}$ i $\mathrm{n}_{\mathrm{z}}=2$ utoliko je bolja ukoliko je veći početni ugao obrušavanja $\theta_{\mathrm{o}}$ (slika 10 ). U slučaju kada je koeficijent normalnog opterećenja $\mathrm{n}_{\mathrm{z}}=\mathrm{n}_{\mathrm{zo}}=$ $\cos \theta_{0}$, dovođenjem ugla bočnog nagiba aviona na vrednost $\gamma= \pm 30^{\circ}$ izaziva se manja promena putnog ugla $\Delta \psi_{\mathrm{t}}$ (isprekidana linija na slici 10). Naravno, pri $\mathrm{n}_{\mathrm{z}}=0$ promena putnog ugla je $\Delta \psi_{\mathrm{t}}=0$.

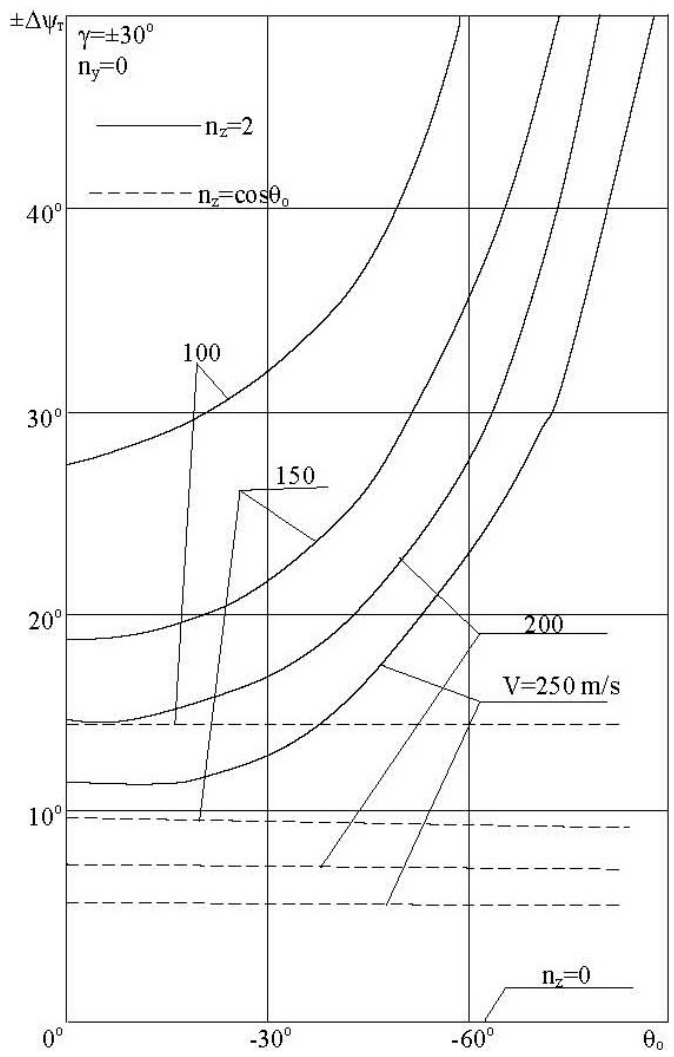

Sl. 10 - Zavisnost promene putnog ugla u funkciji ugla nagiba putanje pri različitim brzinama aviona
Dakle, za povećanje efikasnosti upravljanja avionom pri njegovom dovođenju na cilj u toku obrušavanja, korisno je dovođenje aviona u tačku početka obrušavanja s pravcem vektora brzine malo iznad cilja $(\Delta \theta>0)$. Povećanje koeficijenta normalnog opterećenja za poklapanje vektora brzine sa linijom nišanjenja odgovara uvećanju efikasnosti upravljanja putnim uglom promenom ugla bočnog nagiba aviona. Međutim, u procesu dovođenja aviona na cilj, po uglu promene uzdužnog položaja, moguće je njegovo dovođenje na nulte vrednosti normalnog opterećenja. Upravljanje putnim uglom menjanjem nagiba u tom slučaju nije efikasno. Zbog toga je u toku obrušavanja potrebno koristiti druge funkcije upravljanja, odnosno druge načine stvaranja bočnih sila. Na primer, korišćenje organa neposrednog upravljanja bočnim silama ili promenu ugla klizanja za stvaranje bočnih sila.

Na slici 11 punim linijama prikazane su zavisnosti promene putnog ugla od ugla obrušavanja, koje se obezbeđuju uglom klizanja $\beta= \pm 5^{\circ}$ avionom sa izvodom koeficijenta bočne sile $C_{y}^{\beta}$ koji iznosi $-0,0251 /$ step. Ugao bočnog nagiba aviona pri tom iznosi 0 ; koeficijent bočnog opterećenja $\mathrm{n}_{\mathrm{y}}$ na subsoničnim brzinama ne prelazi 1 .

Isprekidanim linijama na slici 11 prikazana je analogna zavisnost promene putnog ugla $\Delta \psi_{\mathrm{t}}$ od ugla nagiba trajektorije $\theta_{\mathrm{o}}$, koja se obezbeđuje za pet sekundi obrušavanja otklonom organa neposrednog upravljanja bočnim silama. Pri tom je: $\beta=0, \gamma$ $=0, \mathrm{n}_{\mathrm{z}}=0$. Efikasnost neposrednog upravljanja bočnim silama karakteriše se koeficijentima bočne sile $S_{u \text { nubs }}=0,05$. 


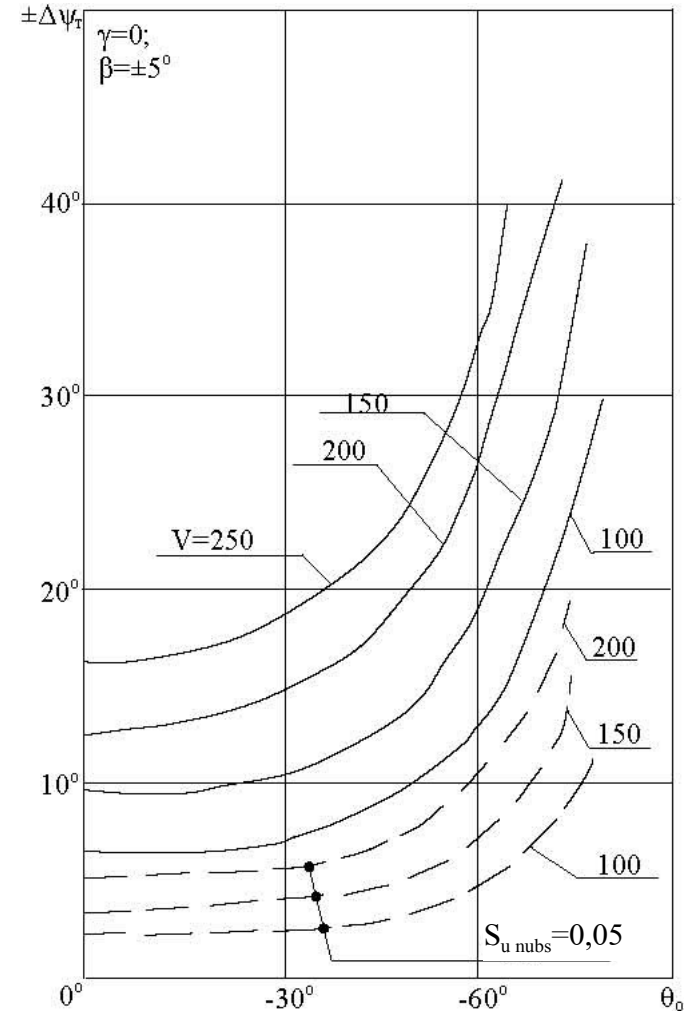

Sl. 11 - Zavisnost promene putnog ugla u funkciji ugla nagiba putanje pri različitim brzinama aviona i pri otklonu organa neposrednog upravljanja bočnim silama

Efikasnost upravljanja bočnim kretanjem aviona ocenjuje se veličinom promene putnog ugla $\Delta \psi_{\text {t }}$, pri stvaranju bočnih sila klizanjem ili organima neposrednog upravljanja bočnim silama. Ona ne zavisi od predznaka normalnog opterećenja, tj. dozvoljava stvaranje negativnih opterećenja bez promene karaktera upravljanja uglom klizanja ili organom neposrednog upravljanja bočnim silama. Takođe, povećava se sa rastom početnog ugla obrušavanja, kao i sa povećanjem brzine leta aviona.

\section{Zaključak}

Uglovi ustaljenog smanjenja visine leta aviona u manevru veći su pri otklonu vektora potiska motora nagore i radu motora na maksimalnom režimu, nego pri izvlačenju vazdušnih kočnica i radu motora na režimu „malog gasa“. Otklonom vektora potiska motora obezbeđuje se oštro obrušavanje aviona na cilj, sve do vertikalnog, bez prekoračenja maksimalno dozvoljene brzine.

Smanjenje normalnog opterećenja sve do nulte vrednosti u procesu upravljanja uglom nagiba trajektorije pri obrušavanju aviona propraćeno je gubitkom efikasnosti upravljanja putnim uglom na račun promene ugla bočnog nagiba aviona.

Upravljanje putnim uglom pri oštrom obrušavanju aviona obezbeđuje se promenom ugla klizanja ili otklonom organa neposrednog upravljanja bočnim silama, čija efikasnost ne zavisi od normalnog opterećenja aviona u obrušavanju.

\section{Literatura:}

[1] Pekić, N.: Optimizacija manevra aviona lovačko bombarderske avijacije pri napadu na tačkaste zemaljske ciljeve, magistarski rad, Mašinski fakultet, Beograd 2004.

[2] Нелюбов, А. И.: Лётные характеристики и боевое маневрирование летательных аппаратов. Выпуск 1. Математическое моделирование движения летательних аппаратов. ВВИА им. Н. Е. Жуковского, 1985.

[3] Тарасенков, А. М.; Брага, В. Г.; Тараненко, В. Т.: Динамика полёта и боевого маневрирования летательных аппаратов. ВВИА им. Н. Е. Жуковкого, 1985. 


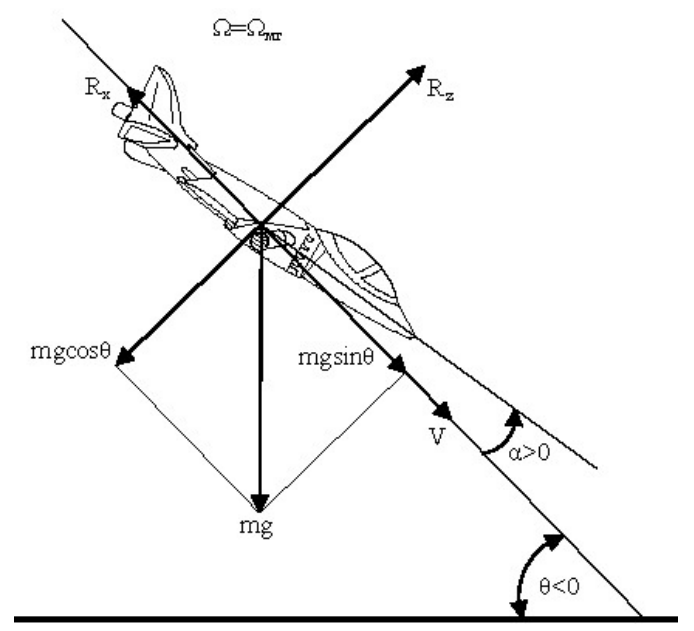

Sl. 1 - Šema sila koje deluju na avion u obrušavanju sa motorima bez vektorisanja potiska, napadni ugao je pozitivan $(\alpha>0)$

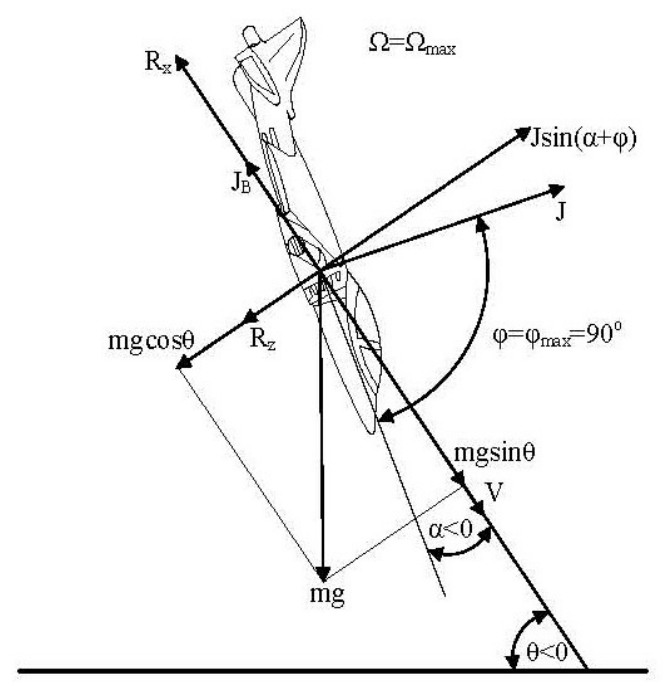

Sl. 2 - Šema sila koje deluju na avion, pri obrušavanju, sa otklonom vektora potiska motora nagore u odnosu na uzdužnu osu aviona 


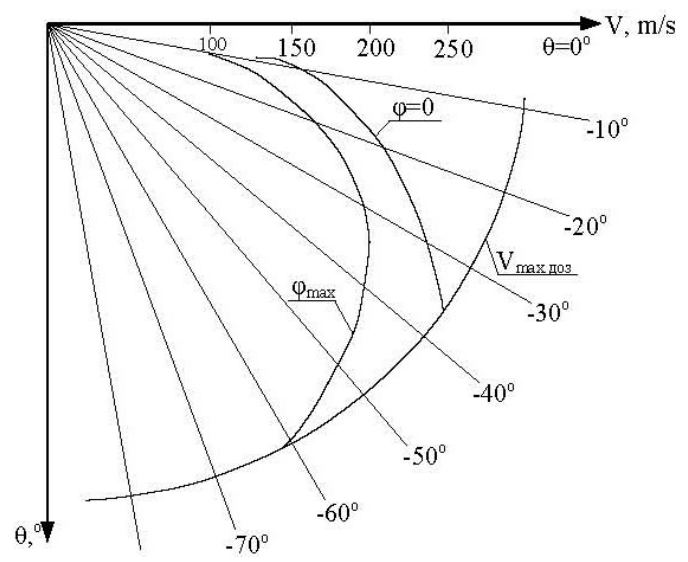

Sl. 3 - Polarni dijagram ustaljenog aviona bez otklona $(\phi=0)$ i sa otklonom vektora potiska motora $(\phi \neq 0)$

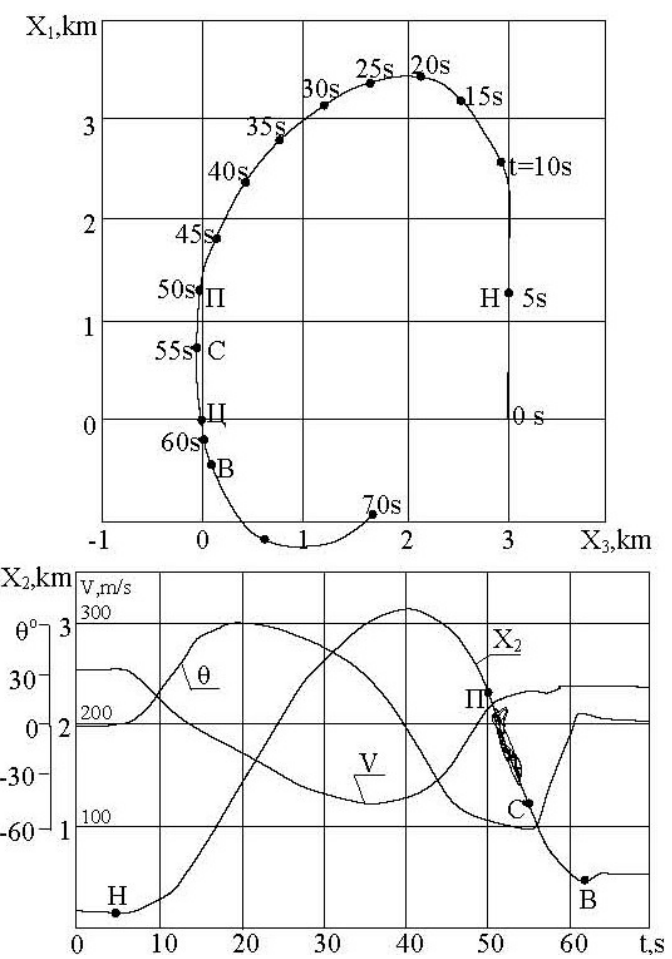

Sl. 4 - Projekcija manevra u horizontalnoj $i$ vertikalnoj ravni i promena parametara leta aviona sa vektorisanim potiskom u manevru 


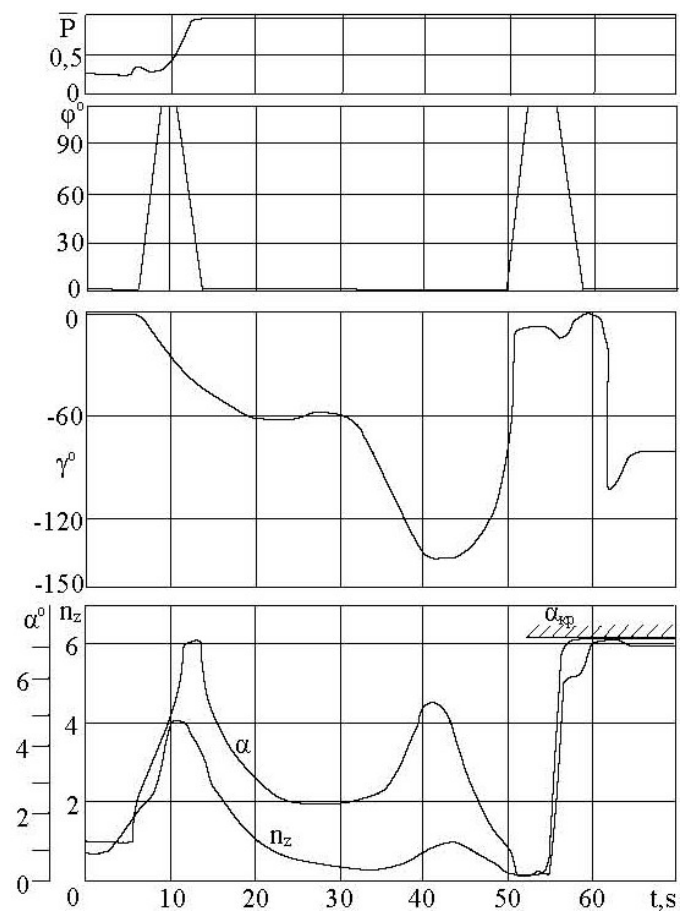

Sl. 5 - Promena parametara leta aviona sa promenom vektora potiska u manevru u funkciji vremena 


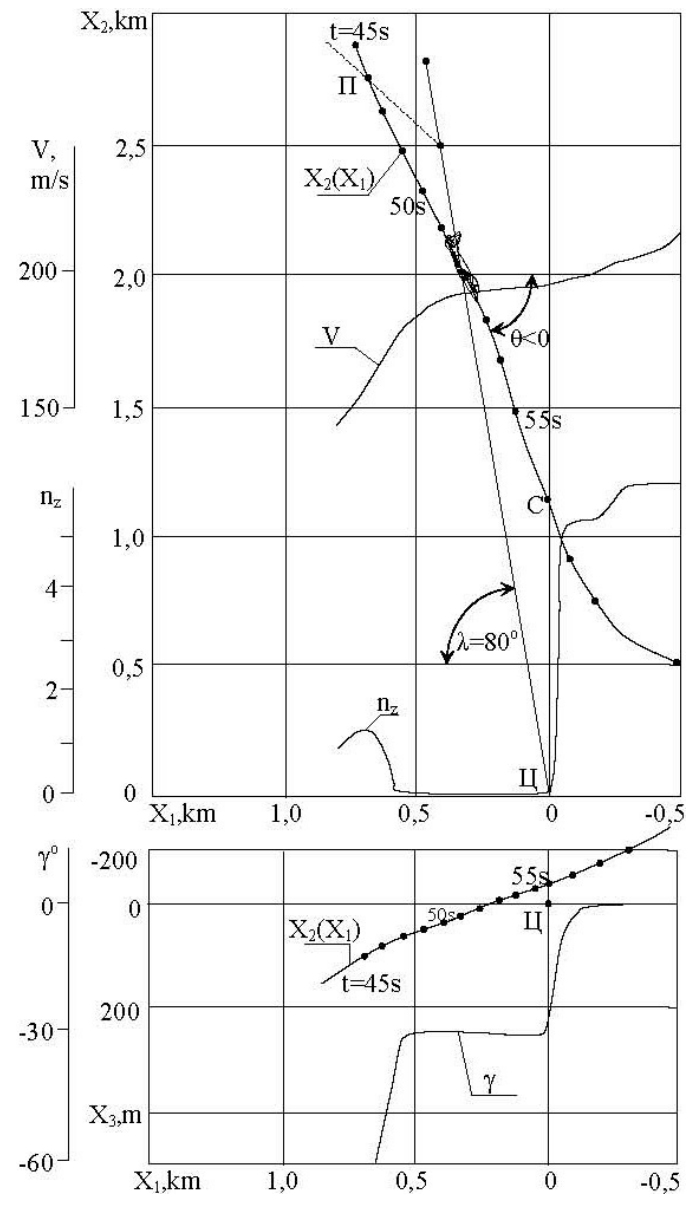

Sl. 6 - Promena parametara leta aviona sa vektorisanim potiskom u obrušavanju u funkciji vremena za zadati ugao obrušavanja od $-80^{\circ}$ 


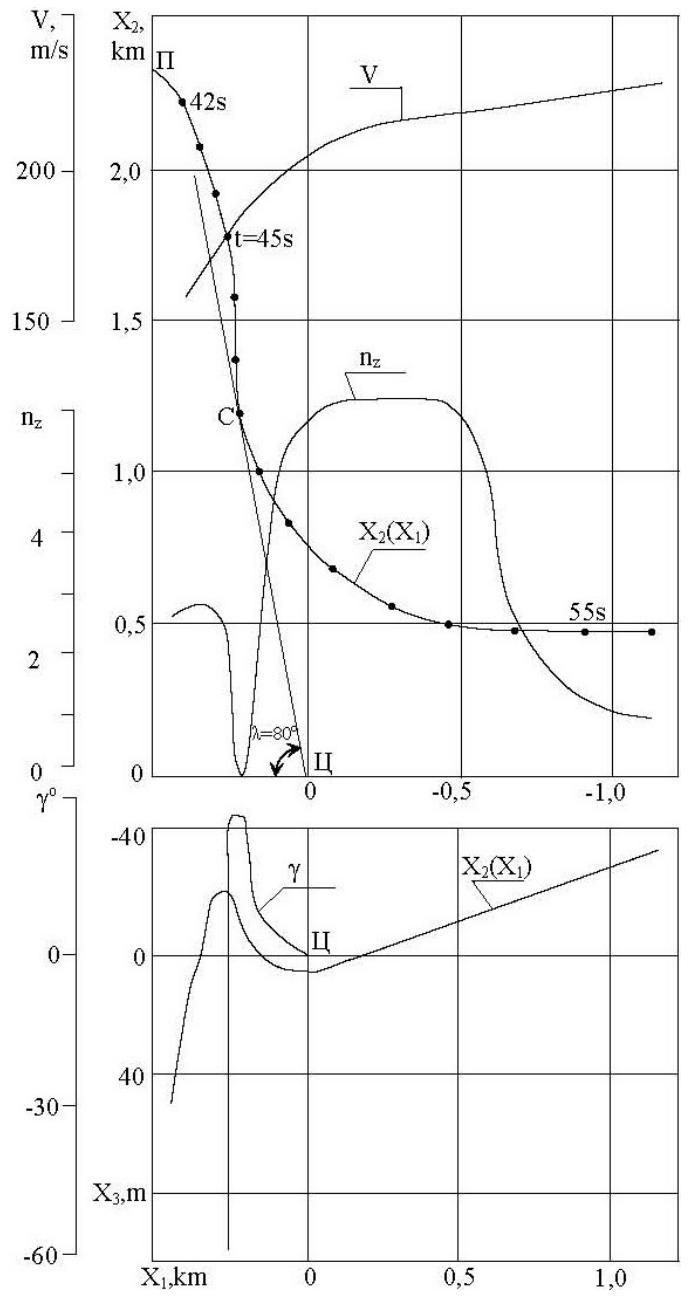

Sl. 7 - Promena parametara leta aviona sa vektorisanim potiskom u završnom delu obrušavanja u funkciji vremena za zadati ugao obrušavanja od $-80^{\circ}$ 


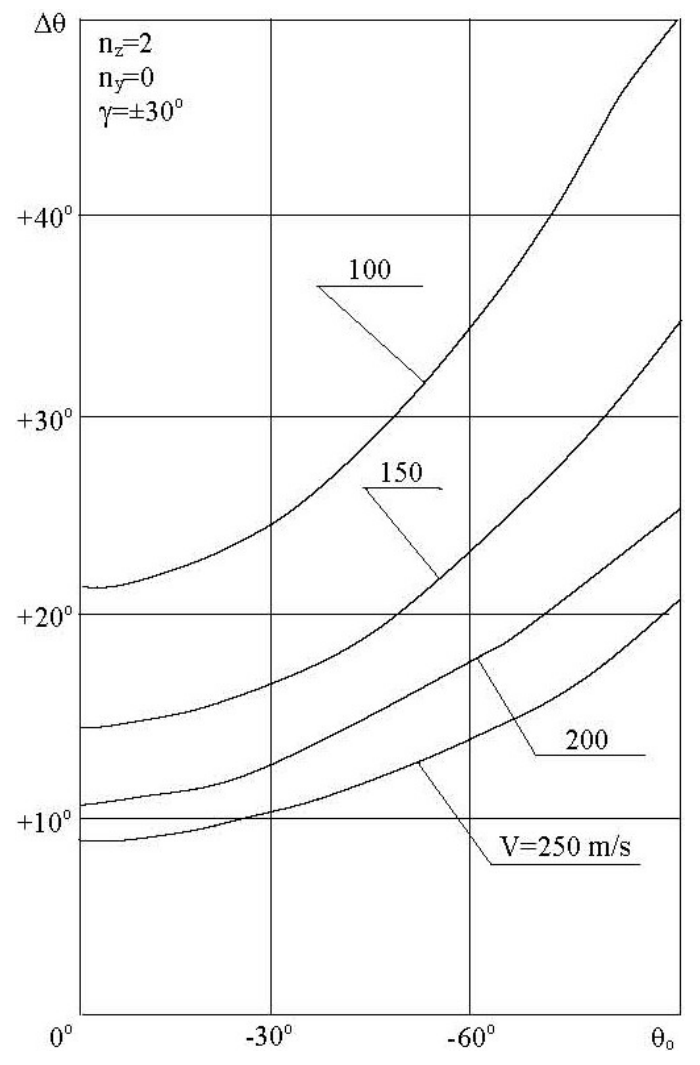

Sl. 8 - Zavisnost prirasta ugla nagiba trajektorije $\Delta \theta>0$ od njegove početne vrednosti $\theta_{o}$ pri $n_{z}=2 ; \gamma=$ $\pm 30^{\circ}$ i nultog bočnog opterećenja $\left(n_{y}=0\right)$ 


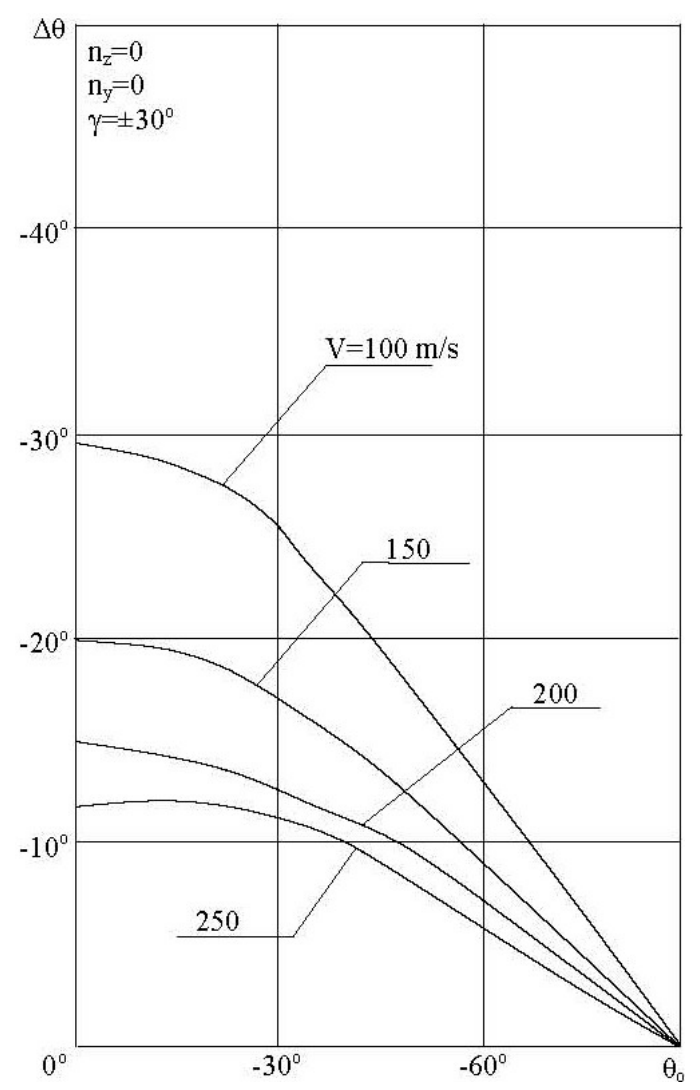

Sl. 9 - Zavisnost negativnog prirasta ugla nagiba trajektorije $\Delta \theta<0$ u odnosu na početni $\theta_{o}$ 


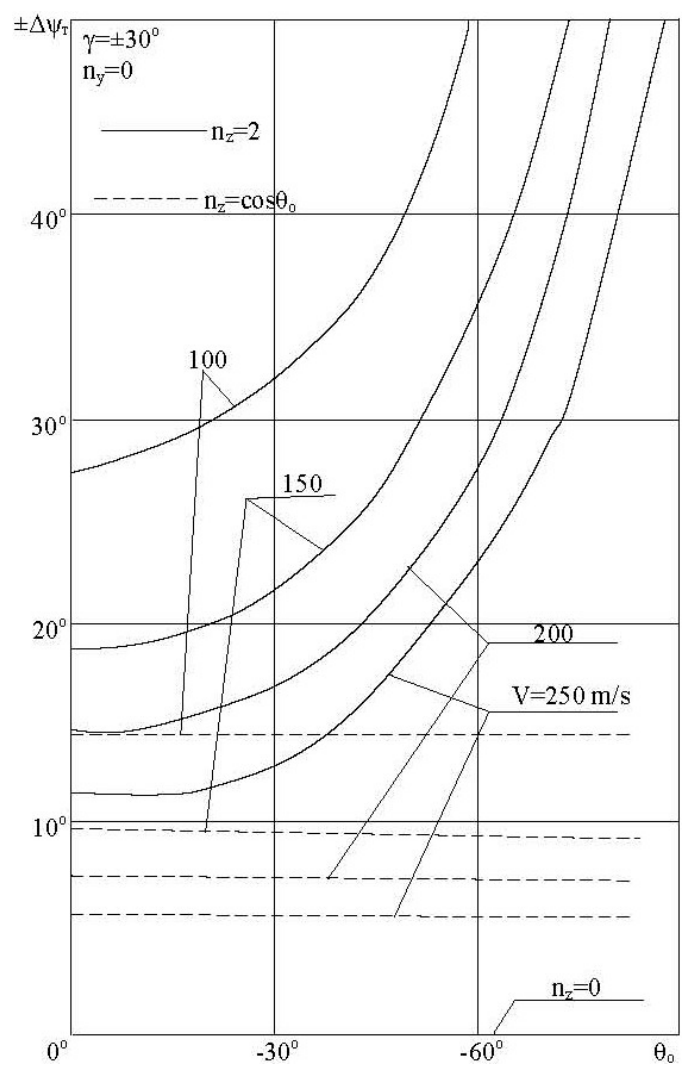

Sl. 10 - Zavisnost promene putnog ugla u funkciji ugla nagiba putanje pri različitim brzinama aviona 


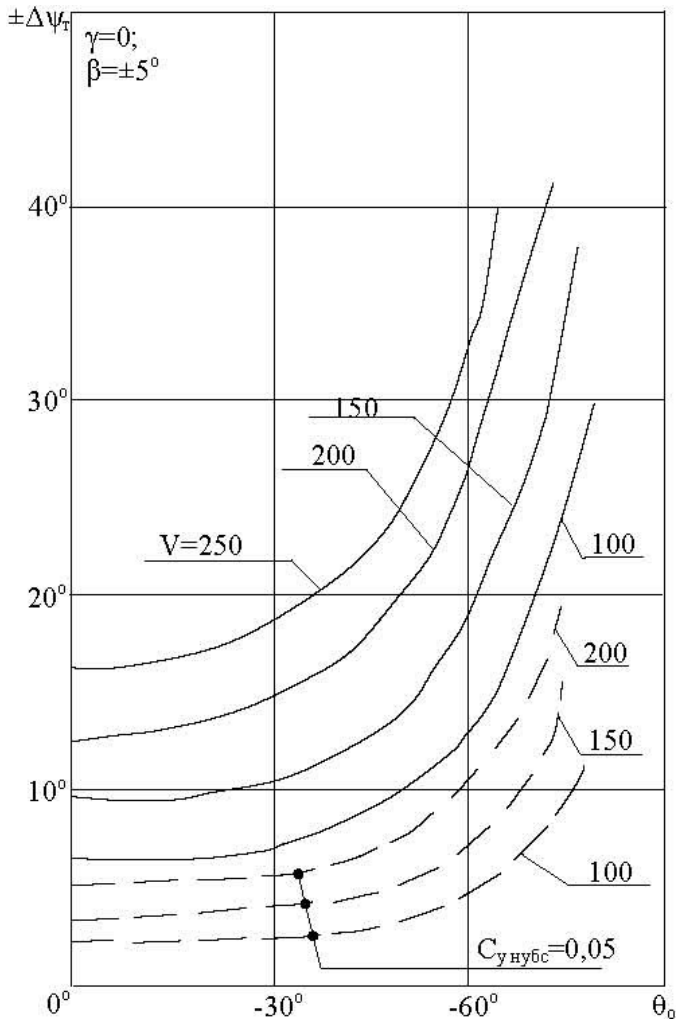

Sl. 11 - Zavisnost promene putnog ugla u funkciji ugla nagiba putanje pri različitim brzinama aviona $i$ pri otklonu organa neposrednog upravljanja bočnim silama 